\title{
ANALISIS RESPON PENGONTROL ON-OFF PADA KENDALI UMPAN BALIK SISTEM FISIS ELEKTRONIK
}

\author{
Darmawan Hidayat $^{1{ }^{1 *} \text {, Meutia Rahmatika }}{ }^{2}$, Nendi Suhendi Syafei ${ }^{3}$ \\ ${ }^{1,3)}$ Jurusan Teknik Elektro, Universitas Padjadjaran \\ 2) Jurusan Fisika, FMIPA, Universitas Padjadjaran \\ e-mail : meutia_rahmatika@yahoo.com,n.suhendi@unpad.ac.id, \\ darmawan.hidayat@unpad.ac.id \\ DOI : 10.24036/eksakta/vol19-iss01/119
}

\begin{abstract}
ABSTRAK
Pengontrol On-Off merupakan salah satu jenis aksi pengontrolan yang banyak digunakan pada kontrol otomatis di industri karena kontrol ini sederhana dan relatif murah. Terdapat dua aspek penting yang harus dipertimbangkan pada pengontrol on-off. Pertama adalah frekuensi osilasi respon yang berpengaruh pada umur ketahanan komponen aktuator. Kedua adalah amplitudo osilasi respon yang memengaruhi besar rugi-rugi energi pada respon sistem kendali keseluruhan. Makalah ini memaparkan suatu strategi dalam mengatur frekuensi dan amplitudo osilasi respon dengan menerapkan histeresis pada bagian pengontrol on-off. Pengaruh parameter waktu tunda (delay) dan penguatan (gain) histeresis terhadap frekuensi dan amplitudo osilasi respon sitem kendali on-off diteliti. Sebagai implementasi, bagian-bagian sistem pengontrol onoff meliputi detektor kesalahan dan waktu tunda histeresis diwujudkan dengan mikrokontroler AT89C51. Saklar elektronik digunakan sebagai model fisis aktuator onoff. Blok sistem proses (plant) dan umpanbalik diwujudkan dengan model fisis elektronik rangkaian resistor dan kapasitor (R dan C) orde satu. Dengan cara ini seluruh besaran fisis yang terlibat adalah berupa tegangan sehingga memudahkan dalam analisis respon sistem kendali on-off karena dapat ditampilkan pada osiloskop guna keperluan pengamatan di laboratorium. Hasil analisis respon dari eksperimen dan simulasi menunjukkan bahwa jika waktu tunda histeresis semakin besar maka frekuensi osilasi menurun namun amplitudo osilasi meningkat dan waktu settling semakin besar. Selain itu, jika penguatan histeresis semakin besar maka frekuensi osilasi respon menurun namun amplitudo osilasi meningkat dan waktu settling semakin cepat. Hasil pengujian menyimpulkan bahwa penerapan histeresis dapat menentukan performansi suatu sistem kendali on-off sehingga pengguna dapat mengatur respon sistem kendali sesuai dengan kriteria pengontrolan yang ditentukan dan diperlukan
\end{abstract}

Kata Kunci : pengontrol on-off, analisis respon, histeresis, model fisis elektronik, mikrokontroler

\section{PENDAHULUAN}

Meskipun perkembangan teknologi kontrol otomatik sangat pesat, pada dasarnya kontrol otomatik terdiri atas dua komponen utama, yaitu sistem (proses) dan pengontrol [1]. Terdapat beberapa aksi kontrol dalam implementasi kontrol otomatik, seperti: on-off, proporsionalintegral-derivatif (PID), fuzzy, dan sejenisnya [2-4].

Pengontrol PID adalah jenis pengontrol proses yang paling luas 
digunakan. Hal ini karena fleksibilitas aksi kontrol pengontrol PID dapat diatur (tune) mengikuti parameter pengontrolan proses yang berubah-ubah. Pengaruh masing-masing parameter $\mathrm{P}, \mathrm{I}$ dan $\mathrm{D}$ terhadap akurasi respon kendali umpanbalik telah ditunjukkan melalui model fisis elektronik [5].

Pengontrol on-off merupakan pengontrol paling sederhana dan tangguh (robust) namun tidak begitu akurat karena variabel kendali (controlled variable) sistem selalu mengandung osilasi. Pengontrol on-off banyak diterapkan pada sistem pengontrolan besaran fisis temperatur sistem pemanas, reaktor fermentasi, ruang klimatik, sistem pemanas ruangan, inkubator untuk bayi, sistem tinggi muka cairan [4, 6-8]. Di rumah tangga pengontrol on-off juga banyak digunakan seperti pada setrika listrik, oven listrik dan pemanas air [6]. Sebagai perbandingan pengontrol on-off, pengontrol fuzzy memberikan konsumsi energi, kegagalan dan kerusakan yang lebih kecil [9]. Namun begitu, implementasi pengontrol fuzzy lebih kompleks dibandingkan pengontrol on-off [2].

Restrepo et al., (2002) melaporkan pengontrol on-off yang diberi waktutunda dapat memperbaiki performansi sistem kendali. Terdapat dua aspek penting yang harus dipertimbangkan pada pengontrol on-off. Pertama adalah frekuensi osilasi respon dan osilasi on-off aktuator yang berpengaruh pada umur ketahanan komponen aktuator. Kedua adalah amplitudo osilasi respon yang memengaruhi akurasi pengendalian dan besar rugi-rugi energi pada respon sistem kendali keseluruhan, yang pada akhirnya mengakibatkan penurunan efisiensi konsumsi energi. Oleh karena itu, diperlukan suatu strategi untuk mengatur parameter frekuensi dan amplitudo osilasi respon. Makalah ini memaparkan suatu strategi dalam mengatur frekuensi dan amplitudo osilasi respon dengan menerapkan histeresis pada bagian pengontrol on-off. Pengaruh parameter waktu-tunda dan penguatan histeresis terhadap frekuensi dan amplitudo osilasi respon dikaji berdasarkan analisis transien dan keadan-mantap sistem kendali.

\section{METODE PENELITIAN}

Gambar 1 memperlihatkan blok diagram untuk analisis performansi dan pengamatan pengaruh histeresis terhadap respon sistem kendali on-off. Blok detektor kesalahan dan histeresis berikut parameter waktu-tunda diwujudkan dengan sebuah mikrokontroler AT89C51 dengan menggunakan bahasa asembli MCS51 (Gambar 1.a dan b). Nilai setting point (SP) dimasukkan ke mikrokontroler sebagai register 8-bit $R 4$ sedangkan nilai umpan balik dinyatakan dalam register 8-bit $R 2$ hasil konversi analog-ke-digital (ADC) dari $H(s)$. Aktuator on-off menggunakan saklar elektronik IC CMOS 4016. Proses $G(s)$ dan umpanbalik $H(s)$ dibuat dalam ordesatu dan diwujudkan dengan menggunakan model fisis rangkaian elektronik resistor dan kapasitor (Gambar 1.d). Dengan cara ini, seluruh besaran fisis yang terlibat adalah berupa tegangan sehingga seluruh sinyal respon sistem dapat diamati dengan mudah pada osiloskop dan selanjutnya dapat dibuat antarmuka ke komputer guna membangun sistem pengendalian berbasis komputer dan keperluan analisis respon sistem [10].

Analisis respon meliputi analisis transien dan keadaan-mantap terhadap sinyal masukan step-satuan. Rangkaian ADC-0804 mengubah sinyal respon $C(s)$ menjadi suatu nilai digital untuk diumpankan ke pengontrol. Pengaruh variasi parameter waktu-tunda dan penguatan histeresis terhadap respon sistem kendali diamati melalui sebuah osiloskop (Combiscope Philips PM3331) 
dan direkam menggunakan kamera digital.

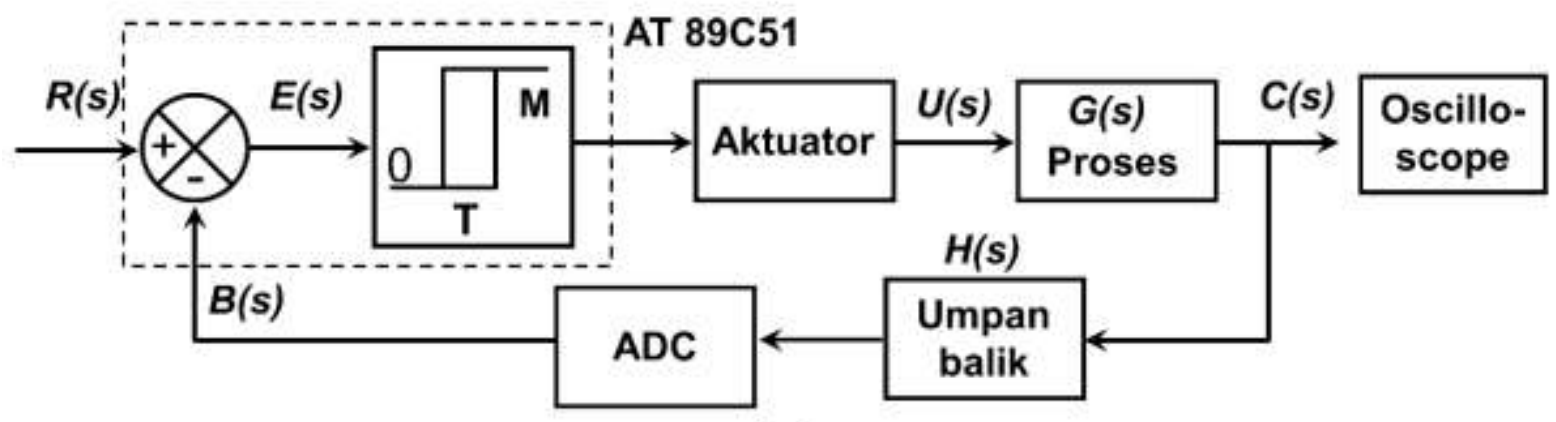

(a)

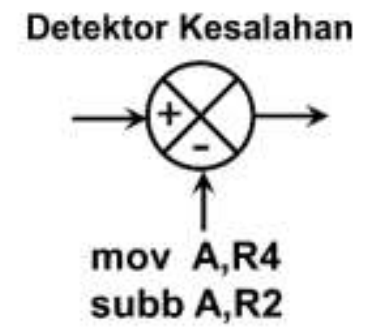

(b)

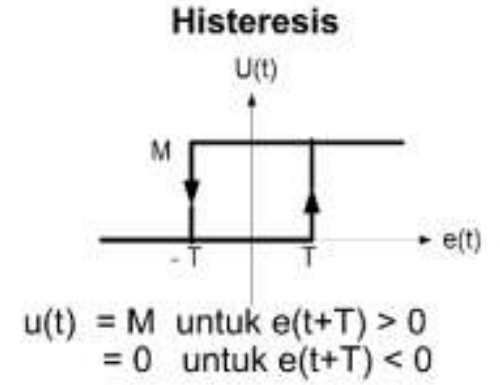

(c)

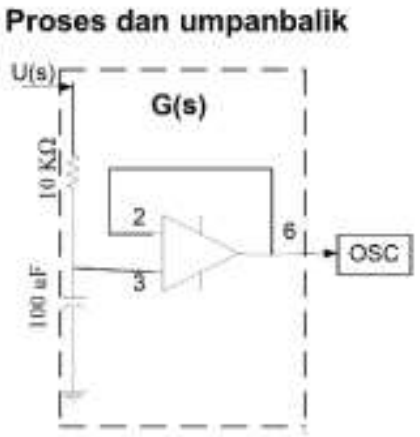

(d)

Gambar 1. Sistem kendali pengontrol on-off (a) skematik diagram, (b) implementasi detektor kesalahan dengan bahasa asembli MCS-51, (c) fungsi histeresis pengontrol dan (d) model fisis proses dan umpan balik yang diwujudkan dengan rangkaian elektronik

\section{HASIL PENELITIAN DAN PEMBAHASAN}

Gambar 2 memperlihatkan pengaruh parameter waktu-tunda histeresis terhadap sinyal aksi $U(s)$ dan sinyal respon $C(s)$. Proses $\mathrm{G}(\mathrm{s})$ adalah $1 /(\mathrm{s}+1)$ dan $\mathrm{H}(\mathrm{s})$ sama dengan satu. Parameter penguatan histeresis adalah $5 \mathrm{~V}$. Untuk waktu-tunda 10 ms (Gambar 2.a), sinyal respon $C(s)$ berada dekat dengan nilai-acuan $R(s)$, yang ditandakan dengan osilasi sinyal respon berada dekat nilai-acuan (nilai $V_{p p}$ sebesar $0.12 \mathrm{~V}$ ). Hasil ini menandakan bahwa akurasi pengontrolan relatif baik. Namun, sinyal aksi $C(s)$ berosilasi dengan frekuensi relatif tinggi yang dapat mengakibatkan penurunan-ketahanan umur komponen aktuator. Dengan memperlambat waktu-tunda menjadi 30 , 50 dan $180 \mathrm{~ms}$ (Gambar 2.b, c dan d) frekuensi osilasi respon dan sinyal aksi (aktuator) menjadi semakin rendah dan waktu-settling semakin cepat. Namun, akurasi pengontrolan semakin turun, yang ditandai dengan meningkatnya amplitudo osilasi respon (nilai $V_{p p}$ membesar) yang mengakibatkan rugi-rugi energi pengontrolan semakin tinggi. Hasil ini menunjukkan bahwa frekuensi osilasi dan amplitudo (akurasi) sinyal respon sistem kendali on-off dapat diatur (ditala) dengan variasi parameter waktu-tunda histeresis [11] 

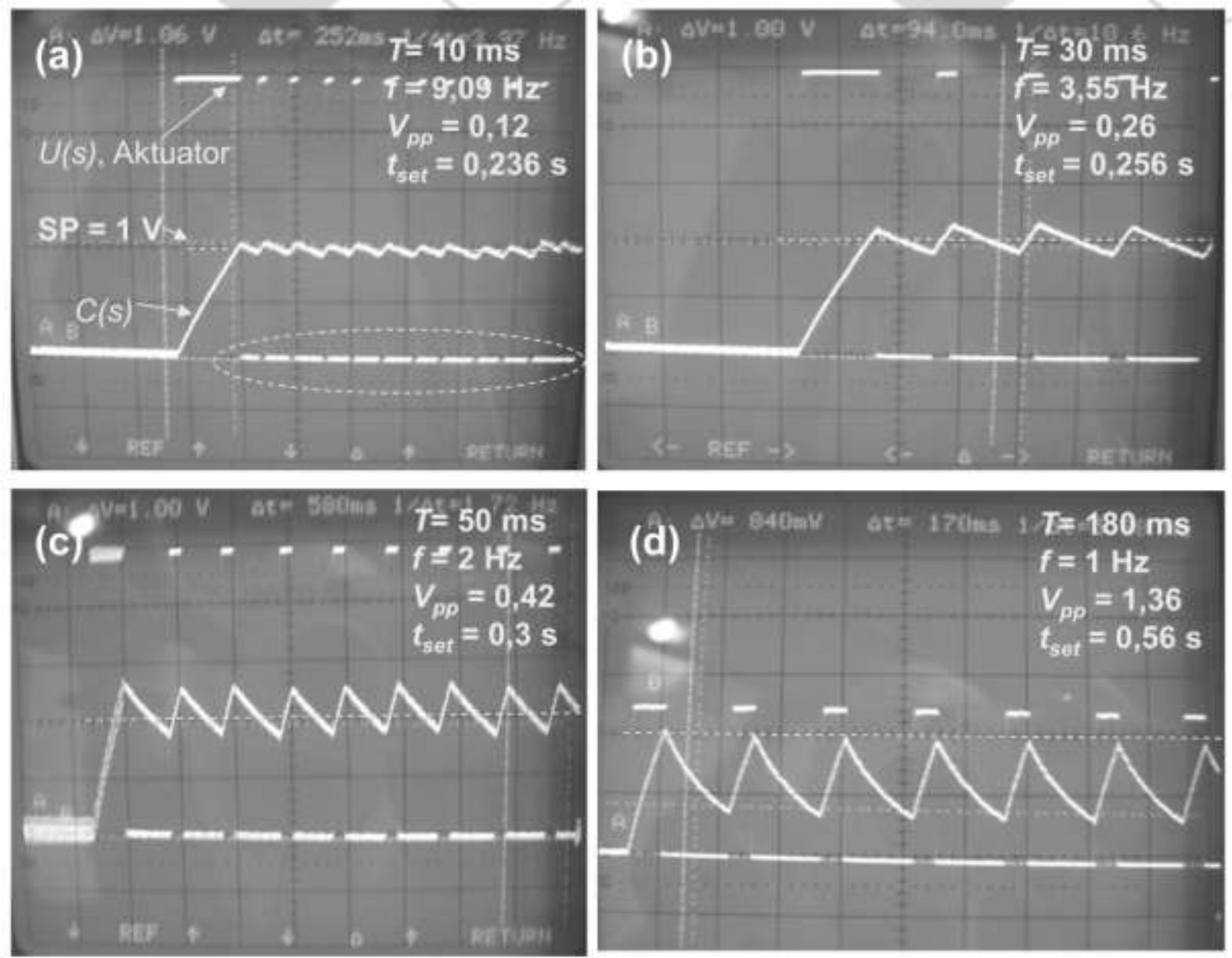

Gambar 2. Pengaruh parameter waktu-tunda histeresis terhadap frekuensi dan amplitudo osilasi respon beserta osilasi aktuator untuk penguatan, $\mathrm{M}$ sebesar $5 \mathrm{~V}$ dan waktu-tunda, $\mathrm{T}$ (a) $10 \mathrm{~ms}$, (b) $30 \mathrm{~ms}$, (c) $50 \mathrm{~ms}$ dan (d) $180 \mathrm{~ms}$

Pengaruh variasi parameter penguatan histeresis $M$ terhadap sinyal aksi $U(s)$ dan sinyal respon $C(s)$ ditunjukkan pada Gambar 3. Proses $G(s)$ adalah $1 /(\mathrm{s}+1)$ dan $H(s)$ sama dengan satu. Parameter waktu-tunda histeresis ditetapkan $30 \mathrm{~ms}$ dan variasi penguatan $M$ adalah 2, 3, 4 dan $5 \mathrm{~V}$. Untuk penguatan sebesar $2 \mathrm{~V}$ (Gambar 3.a), frekuensi dan amplitudo osilasi respon masing-masing adalah $6.4 \mathrm{~Hz}$ dan 0.12 $\mathrm{V}$, dengan waktu-settling $0.7 \mathrm{~s}$. Dengan meningkatkan nilai penguatan histeresis menjadi 3, 4 dan $5 \mathrm{~V}$ (Gambar 3.b, c dan d), frekuensi osilasi menurun, amplitudo osilasi meningkat dan waktu-

settling semakin cepat. Hasil ini menunjukkan bahwa dengan memperbesar penguatan histeresis, osilasi aktuator makin rendah, akurasi pengendalian menurun ditunjukkan dengan meningkatnya nilai $V_{p p}$ meningkat dan waktu-respon semakin baik ( $t_{\text {set }}$ makin cepat) [12]. Nilai $M$ pada model fisis aktual implementasi menyatakan besaran daya yang diberikan kepada aktuator. Dengan memperbesar nilai $M$ maka memperbesar daya yang diberikan ke aktuator sehinga dapat mengatur laju besaran fisis respon sistem. Oleh karena itu, respon sistem semakin cepat ( $t_{\text {set }}$ yang kecil). 

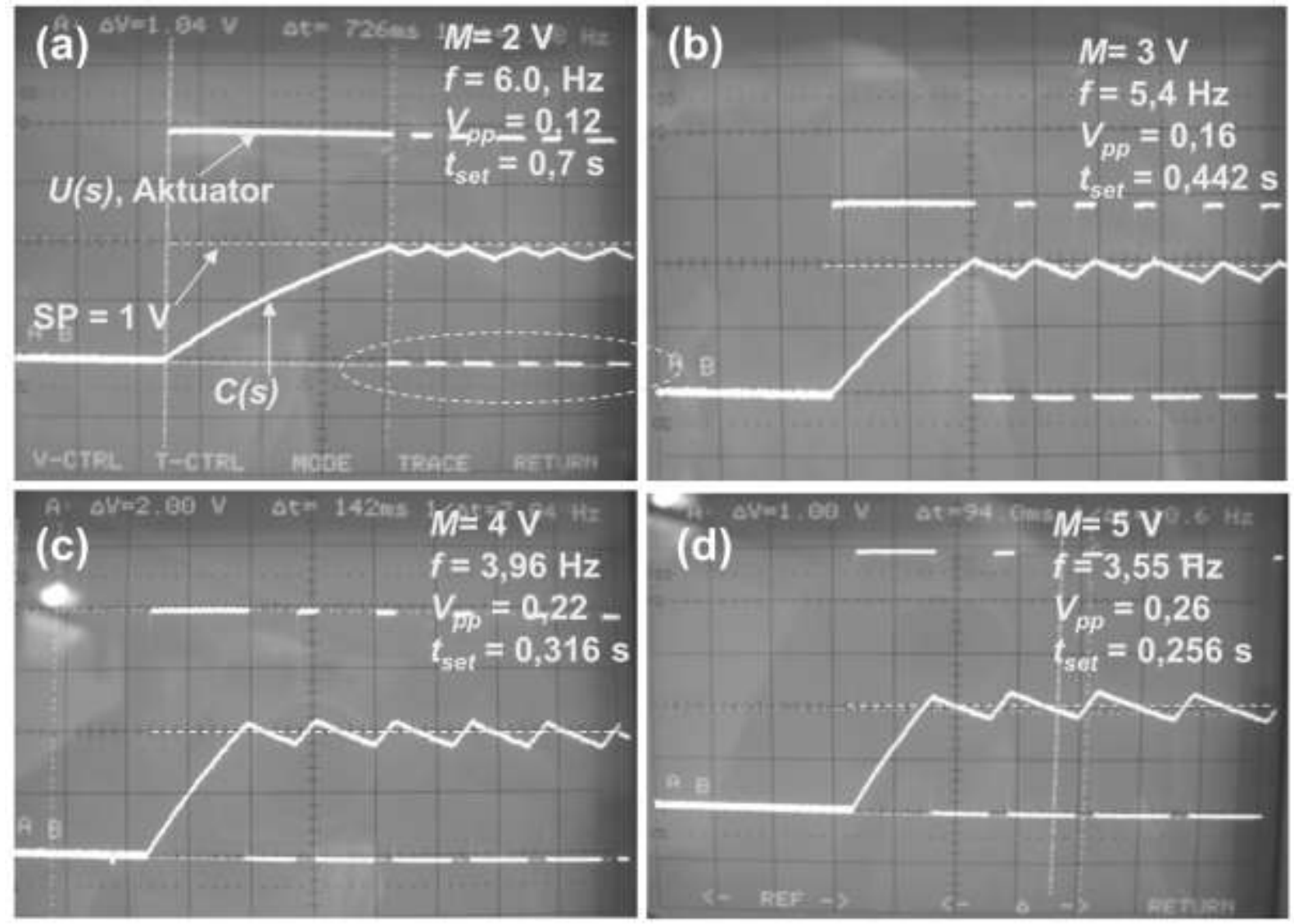

Gambar 3. Pengaruh parameter penguatan histeresis terhadap frekuensi dan amplitudo osilasi respon beserta osilasi aktuator untuk waktu-tunda $30 \mathrm{~ms}$ dan variasi penguatan, $M$ sebesar (a) $2 \mathrm{~V}$, (b) $3 \mathrm{~V}$, (c) $4 \mathrm{~V}$ dan (d) $5 \mathrm{~V}$

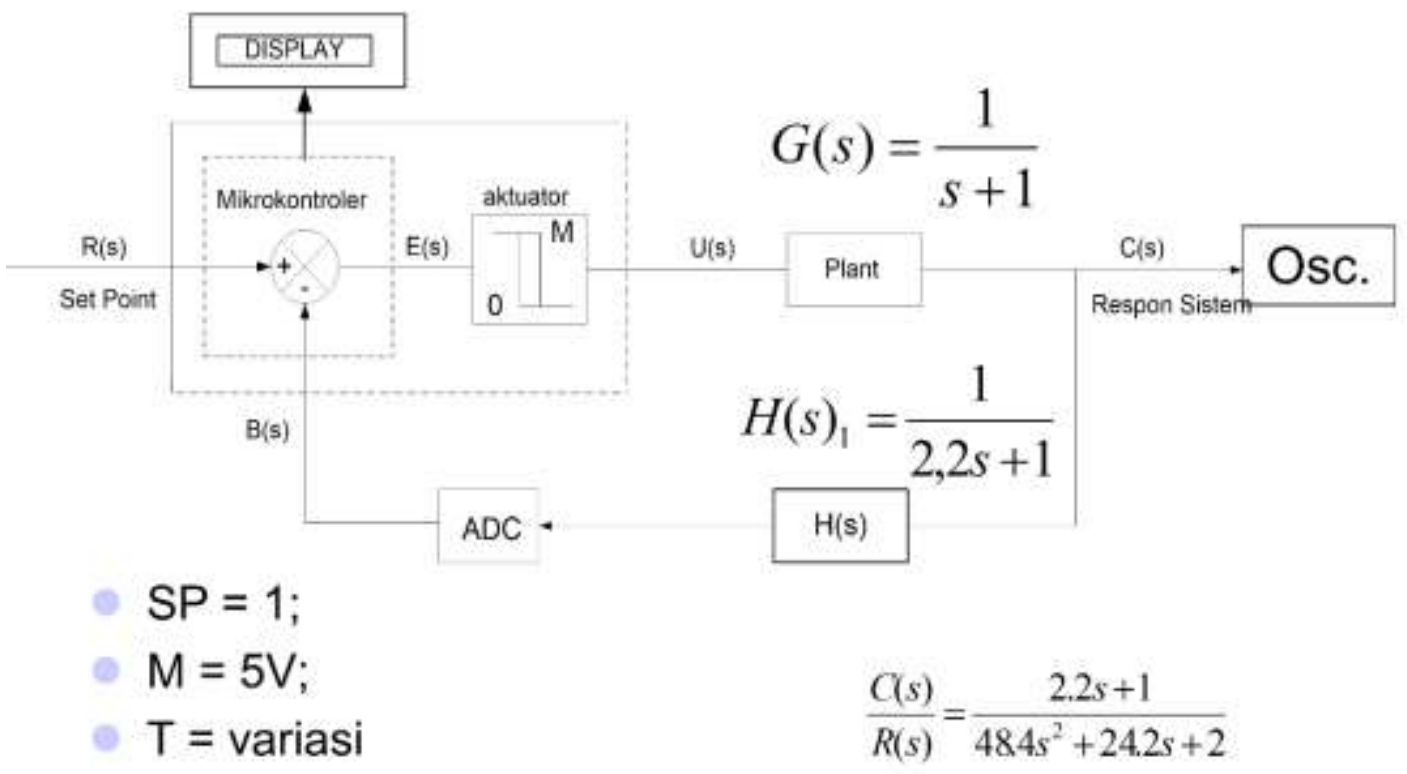

Gambar 4. Pengujian pengaruh delay histeresis dengan komponen umpan balik ordesatu 
Pengaruh parameter delay pengontrol on-off dengan komponen umpan balik $H(s)$ bukan orde-nol terhadap respon pengontrolan frekuensi osilasi, amplitudo dan waktu settling respon diperlihatkan pada Gambar 4. Proses $G(s)$ adalah $1 /(\mathrm{s}+1)$ dan $H(s)$ adalah $1 /(2,2 s+1)$ sehingga fungsi transfer sistem keseluruhan adalah seperti Persamaan 1.

$$
\frac{C(s)}{R(s)}=\frac{2.2 s+1}{48.4 s^{2}+24.2 s+2}
$$

Gambar 5 menunjukkan hasil pengujian dengan komponen umpan balik $\mathrm{H}(\mathrm{s})$ adalah $1 /(2,2 \mathrm{~s}+1)$. Nilai parameter delay divariasikan $0,5,1,1,5$ dan $2 \mathrm{~s}$ dengan nilai gain pengontrol, $\mathrm{M}$ sebesar 5 V.

Ketika delay divariasikan $0,5-2$ sekon, frekuensi osilasi respon menurun
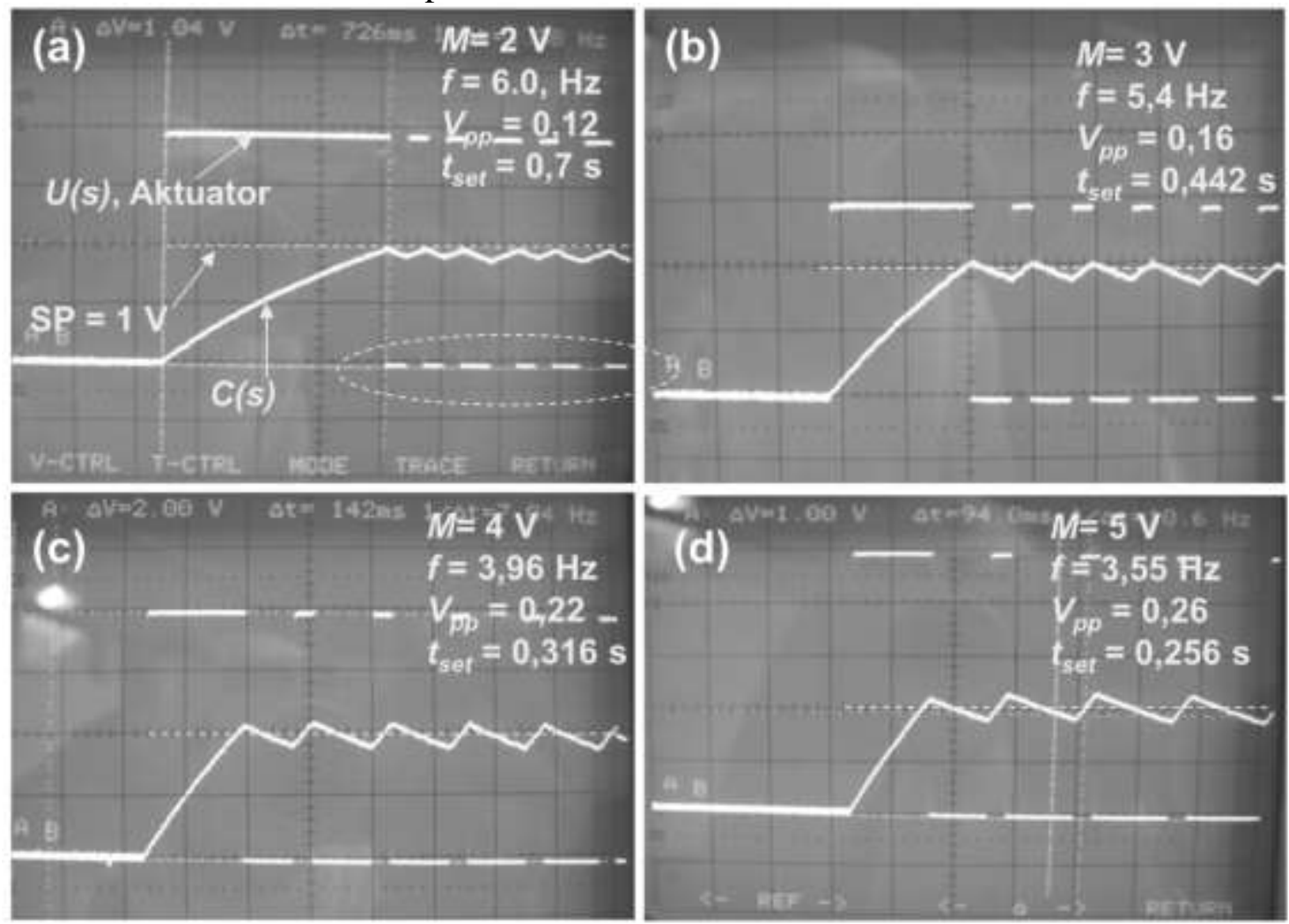

Gambar 5. Pengaruh parameter penguatan histeresis terhadap frekuensi dan amplitudo osilasi respon beserta osilasi aktuator untuk waktu-tunda $30 \mathrm{~ms}$ dan variasi penguatan, $\mathrm{M}$ (a) $2 \mathrm{~V}$, (b) $3 \mathrm{~V}$, (c) $4 \mathrm{~V}$ dan (d) $5 \mathrm{~V}$ 


\section{KESIMPULAN}

Hasil pengujian menunjukkan bahwa osilasi CV pada sistem kendali umpan balik pengontrol on-off dapat diatur melalui pengaturan dua parameter penguatan $\mathrm{M}$ dan histeresis pengontrol on-off. Nilai penguatan M semakin besar menyebabkan waktu settling semakin cepat dan penurunan osilasi $\mathrm{CV}$ namun meningkatkan amplitudo osilasi.

Untuk memperkecil osilasi CV dapat dilakukan dengan menurunkan nilai delay histeresis pengontrol on-off. Berdasarkan hasil penelitian dapat disimpulkan bahwa performansi suatu sistem kendali umpan balik dengan pengontrol on-off dapat diatur melalui dua parameter penguatan dan delay histeresis untuk memenuhi kriteria pengontrolan yang ditentukan dan diperlukan.

\section{DAFTAR PUSTAKA}

Tomáš Uriča, Anna Simonová. Simulation of an on-off controller for systems of second order with the use of LabVIEW. Procedia Engineering 192 (2017) 905 - 910.

E. Mirzaee-Ghaleh, M. Omid, A. Keyhani, M.J. Dalvand. Comparison of fuzzy and on/off controllers for winter season indoor climate management in a model poultry house. Computers and Electronics in Agriculture 110 (2015) 187-195.

Chang-Soon Kang, Chang-Ho Hyun, Mignon Park. Fuzzy logic-based advanced on-off control for thermal comfort in residential buildings. Applied Energy 155 (2015) 270-283.

Giulia Ulpiani, Matteo Borgognoni, Alessandra Romagnoli, Costanzo Di Perna. Comparing the performance of on/off, PID and fuzzy controllersapplied to the heating system of an energy-efficient building. Energy and Buildings 116 (2016) 1-17.
Darmawan Hidayat, Eppstian Syah As'ari, Nendi Suhendi Syafei. Implementasi pengontrol PID pada model fisis elektronik. Eksakta 18:2 (2017) 178 185.

Yemao Li, Jianjun Xia. An on-off control strategy to reduce return water temperature. Energy Procedia 116 (2017) 452 - 459 .

Restrepo, A., González, A., Orduz, S. 2002. Cost effective control strategy for small applications and pilot plants: on-off valves with temporized PID controller. Chem. Eng. J., 89: 101-107.

U. Hoffmann, U. Muller, B. Schurmann and H. Rake. An on-off self-tuner development, realtime application and comparison to conventional onoff controllers. IFAC Proceedings Volumes 17:2 (1984) 2777 - 2782.

Sina Faizollahzadeh Ardabili, Asghar Mahmoudi, Tarahom Mesri Gundoshmian, Ali Roshanianfard. Modeling and comparison of fuzzy and on/off controller in a mushroom growing hall. Measurement 90 (2016) 127-134.

Whyman, D. An Introductory Experiment in automatic Process Control Using A Microcomputer as Controller. Comput. Edu., 12:4 (1988) 493-500.

Abdul Afram, Farrokh Janabi-Sharifi. Effects of dead-band and set-point settings of on/off controllers on theenergy consumption and equipment switching frequency of aresidential HVAC system. Journal of Process Control 47 (2016) 161174.

J. Dostal, L. Ferkl. Model Predictive Control of Climatic Chamber with On-off

Actuators. IFAC Proceedings Volumes 47:3 (2014) 4423 - 4428. 